\section{Henge manufacture}

SIR - As a mining engineer engaged, like my colleague of some four millennia ago, in the acquisition and carving of stones for a henge, albeit at only half his scale, I have perforce been studying his work.

Two points seem to have been missed in discussion of the original Stonehenge. The first is the mysticism concerning the number 19. G.S. Hawkins has suggested that its relevance was to the period of swing of the Moon, about 18.6 years (Stonehenge Decoded, Fontana, London). A simpler reason would be if the Hyperborean month were 19 days. The symbolism of this is that, allowing for 4 feast days, which would be time out of normal work (midwinter, the equinoxes and midsummer), this gives us 19 such months in the year. This fortuituous combination of the $19 \mathrm{~s}$ would be marked and relate to the 19 bluestones of the inner circle.

The second point deals with transportation. Common opinion suggests that the stones were manually hauled to the site. But surely if oxen were available to provide shoulder blades for shovels, they would also be present to provide haulage for the stones. Given that oxen can pull between 1,200 and 4,000 pounds weight, depending on where they fit in the scale between modern oxen and buffalo, this would reduce the haulage team from 700 men to 15 to 50 animals. In my colleague's defence, I propose this as a much more likely option than that commonly accepted.

\section{Rock Mechanics and}

DAVID A. SUMMERS

Explosives Research Center, University of Missouri-Rolla, Rolla, Missouri 65401, USA

\section{Japanese IQ}

SIR - Richard Lynn' agrees with me that the value for mean Japanese IQ should be dropped from the 111 of his original article $^{2}$ to 106.6, assuming that Americans have made IQ gains at the rate claimed. That rate has now been supported by a massive body of data ${ }^{3}$. He also offers an adjustment for the urban bias of the Japanese sample which, if the missing rural subjects were 7 points below national norms, would reduce Japanese IQ to 104.4

However, the allowance for urban bias may not be sufficient. The sample not only had no subjects from villages or small towns but also under-represented Japanese from cities less than 50,000 in population ${ }^{4}$. The sample represented only the upper 70 per cent of the population on an urban-rural scale and if the extra missing subjects were even 3 points below national norms, Japanese IQ would fall to 103.9: 106.6(.696) $+100.9(.063)+96.9(.241)=103.9$

More important, Lynn makes no allowance for possible bias for socioeconomic status (SES) in the sample, a possibility suggested by the fact that no effort was made to stratify for this
Bureaux (CAB), which publishes a large series of abstract journals covering the literature on agriculture and related fields (the consolidated machine-readable database is known as $C A B$ Abstracts), is reviewing its policy on conference abstracts. While full papers in conference proceedings will continue to be dealt with like any paper in a primary journal, we need to consider whether individual conference abstracts should be included (the full proceedings will still be cited). Before a final decision is made on this matter, comments from both researchers and database users would be helpful. J.R. METCALFE Commonwealth Agricultural Bureaux, Farnham House, Farnham Royal, Slough SL2 3BN, UK

significance.

As Lynn points out, evidence on urbanrural differences is mixed ${ }^{\prime}$, and the sample may have been substandard rather than elite for SES. But we just do not know and should await better evidence before giving estimates of Japanese IQ. It is inevitable that textbooks over the next decade will refer to a mean of 111 but the profession should do all in its power to provide an antidote.

JAMES R. FLYNN

\section{Department of Political Studies,}

\section{University of Otago, New Zealand}

I. L.ynn, R. Nature 306, 292 (1983)

2. Lynn, R. Nature 297, 222 (1982)

3. Flynn, J.R. Psychol. Bull. 95. 29-51 (1984).

4. Stevenson. H.W. \& Azuma, H. Nature 306, 291 (1983).

5. Mohs, M. Discover, 20 September (1982).

- Correspondence on this matter is now closed - Editor.

\section{Why abstract?}

SIR - In drawing attention to the increasing extent to which abstracts of papers delivered verbally at conferences are being published in scientific journals, M.A. Bray (Nature 307, 206; 1984), bemoaned the fact that large numbers of citations of individual conference abstracts tend to appear among references retrieved by computerized literature searches. You suggest that database compilers might admit as search criteria Boolean specifications such as "not abstract"'. Would it not be better, however, to consider whether abstracttype papers should be included in such databases in the first place?

Those who favour their inclusion would argue (1) that an abstract from a conference may be the only record of a piece of research, (2) that it gives notice of research results long before they are written up in full, or (3) that since abstracts are often cited in research papers they must be accorded some scientific value.

Those who think abstracts should not be included would argue (1) that they are generally only interim summaries of ongoing research which will be written up in full in due course, (2) that they are of ten not backed up by fuller reports and so represent only a minimal form of publication or (3) that database compilers should concentrate on conventional primary literature.

The Commonwealth Agricultural

\section{Last amateur}

$\mathrm{SIR}_{\mathrm{R}}$ - It is unfortunate that your " 100 Years ago" on William Barlow's first paper on the relations of crystal structure to symmetry' failed to give him credit by name. Barlow, one of the last in the English tradition of talented self-taught "amateurs", went on to devise a completely original formulation of 230 crystal space groups ${ }^{2}$ that was pre-empted by the slightly earlier publications of E.S. Fedorov and Artur Schönflies. His theoretical models of crystal structure, like those you reprinted, inspired W.H. and W.L. Braggs' actual solution of crystal structures by X-ray diffraction. But his valence theory of 1906-10 (with W.H. Pope of Cambridge) was far off the mark, and the new theories of crystal structure passed him by. He did not publish anything further after 1915 although he lived until $1934^{3}$, but he deserves to be remembered as one of the completely original minds of his time.

Department of Geology,

University of Oregon,

Eugene, Oregon 97403, USA

Nature 306,43 (1983)

2. Barlow, W. Z. Kristallogr. 23, 1-63 (1894).

\section{Count down}

SIR - In the jargon of radiation detector technology, "count" is used correctly as a verb, but also perversely to describe the event or pulse so counted and, with slightly more justification, for the act of counting for a chosen period and for the result. Thus instructions to a student might read:

"take thirty 30-second counts, record the number of counts for each count, and calculate the average number of counts per second"'.

That students can nevertheless perform the experiment correctly is an indication that they have been exposed to such misusage from an early age and accept it as normal.

One should count pulses, and restrict the counting of counts to statistical studies of European nobility.

R. F. ENTwisti.E

Department of Physics,

University of Otago,

Box 56, Dunedin, New Zealand 